\title{
Voluntary and involuntary psychiatric admissions in a suburban area: comparison with national rates, diagnosis and other correlates of involuntary admission status
}

\author{
J. Gilhooley , E. Umama-Agada ${ }^{2}$, M. Asghar ${ }^{2}$, S. McManus², P. F. Whitty ${ }^{2}$ and B. D. Kelly ${ }^{2 *}$ \\ ${ }^{1}$ St. Patrick's University Hospital, James Street, Dublin, D08 K7YW, Ireland \\ ${ }^{2}$ Department of Psychiatry, Trinity College Dublin, Trinity Centre for Health Sciences, Tallaght Hospital, Dublin, D24 NR0A, Ireland
}

\begin{abstract}
Objectives. To establish if the relatively low rate of involuntary psychiatric admission in a suburban area between 2007 and 2011 was maintained in 2014/2015, and explore key correlates of involuntary status.

Methods. We used existing hospital records and data sources to extract rates and selected potential correlates of voluntary and involuntary admission in south west Dublin (catchment area: 273419 people) over 18 months in 2014/2015 and compared these with published national data from the census and Health Research Board.

Results. The rate of involuntary admission in the suburban area studied between 2007 and 2011 was 33.8 involuntary admissions per 100000 population annually, which was lower than the national rate (48.6). By 2014/2015, the rate of involuntary admission in this area had risen to 46.8 involuntary admissions per 100000 population annually, similar to the national rate (44.9). Nevertheless, the overall (voluntary and involuntary) admission rate in the suburban area (346.7 admissions per 100000 population annually) was still lower the national rate (387.9), owing to a lower rate of voluntary admission in the suburban area (299.9) compared to Ireland as a whole (342.9). Multi-variable testing demonstrated that diagnosis was the strongest driver of involuntary admission in the suburban area: this area had 28.5 involuntary admissions per 100000 population annually with schizophrenia or related disorders, compared to 18.9 nationally. Schizophrenia and related disorders accounted for $60.9 \%$ of involuntary admissions in the suburban area compared to $42.1 \%$ nationally.
\end{abstract}

Conclusions. Schizophrenia is the strongest driver of involuntary admission in the suburban area in this study.

Received 28 May 2017; Revised 30 June 2017; Accepted 6 July 2017; First published online 24 August 2017

Key words: Legislation, mental disorder, psychiatry, Ireland.

\section{Introduction}

Involuntary inpatient psychiatric care has been a long-standing feature of mental health services in all countries for which there is recorded history (Kelly, 2016). The process of involuntary admission generally involves a combination of clinical assessments and specific legal procedures to ensure care is provided and rights are respected (Gostin et al. 2010).

Rates of involuntary admission vary significantly between and within countries (Zinkler \& Priebe, 2002; Salize \& Dressing, 2004). Overall, involuntary status is commonly associated with a diagnosis of psychosis and police involvement in admission ( $\mathrm{Ng} \&$ Kelly, 2012; Van der Post et al. 2012). In Ireland, involuntary admission is also associated with male gender, a

* Address for correspondence: B. D. Kelly, Department of Psychiatry, Trinity College Dublin, Trinity Centre for Health Sciences, Tallaght Hospital, Dublin, D24 NR0A, Ireland.

(Email: brendan.kelly@tcd.ie) diagnosis of schizophrenia or related disorders (Cunningham, 2012; Ng \& Kelly, 2012), and reduced insight (Kelly et al. 2004).

Involuntary admission in Ireland is governed by the Mental Health Act 2001, which has had a significant impact on some but not all aspects of mental health services since full implementation in 2006 (Kelly, 2007; Murray et al. 2009; Nwachukwu et al. 2010; Ng \& Kelly, 2012; Ramsay et al. 2013; Kelly et al. 2015; Georgieva et al. 2016; Smyth et al. 2016). In 2014, there were 17797 admissions to Irish psychiatry inpatient facilities, which yields a rate of 387.9 admissions per 100000 population (Daly \& Walsh, 2015). Of these, $2066(11.6 \%)$ were involuntary, reflecting an involuntary admission rate of 45.0 per 100000 population in that year.

Even within Ireland, however, involuntary admission rates vary between areas and over time. Between 2007 and 2011, the rate of involuntary admission in south west Dublin (a suburban area) was 33.8 per 100000 population 
per year, which was notably lower than the national rate (48.6 per 100000 population per year) (McManus et al. 2015). In sharp contrast, the involuntary admission rate in Dublin's north inner-city was 71.2 per 100000 population per year between 2008 and 2014, which was higher than both the national rate and the rate in the suburban area (Curley et al. 2016).

These differences may relate to a number of factors. The service in Dublin's north inner-city, for example, covers a catchment area of 33000 people with levels of deprivation that are three times higher than the national average, with $51 \%$ of residents in the lowest possible social class (class 10) ( $\mathrm{Ng} \&$ Kelly, 2012). Service factors could also be relevant to differences between these areas, including greater homecare and assertive outreach in the south west Dublin suburban area, and possibly greater use of private inpatient beds. More data are needed to explore these possibilities.

The purposes of the present study were to examine rates of voluntary and involuntary admission in south west Dublin suburban area in 2014/2015; to see if the relatively low rate of involuntary admission in 2007-2011 was maintained in this area; and to explore key correlates of involuntary status in this service to try to explain why rates in this area might differ over time or differ from national rates.

\section{Methods}

\section{Setting}

We studied all voluntary and involuntary admissions to the Acute Psychiatric Unit in Tallaght Hospital, Dublin (south west Dublin) between 1 January 2014 and 30 June 2015 (inclusive). This is a 52-bed admission unit for the Dublin South West and West Mental Health Service, a public sector general adult psychiatry service serving a catchment area of 273419 people. This mental health service includes four multidisciplinary general adult psychiatry teams, one old age psychiatry service and one rehabilitation/assertive outreach service.

The inpatient unit is part of a large general hospital (i.e. with medical and surgical patients) and provides care for acute mental illness in adults (aged 18 years or over), including both voluntary and involuntary patients under the Mental Health Act 2001. Children (i.e. people aged under 18 years) are occasionally admitted when there are no appropriate child and adolescent inpatient facilities available.

\section{Data collection}

For all admissions from 1 January 2014 to 30 June 2015, we recorded gender, date of birth, occupation, marital status, date of admission and date of discharge. We recorded clinical discharge diagnosis using the International Classification of Diseases, Volume 10 (World Health Organisation, 1992). We selected these variables owing to both their possible relevance to admission status and the fact that they were available from existing hospital data sources.

For patients whose status was involuntary for part or all of their admission, we recorded the date their status became involuntary and the criteria upon which this was based, as outlined in Section 3(1) of the Mental Health Act 2001, as follows: (a) 'because of the illness, disability or dementia, there is a serious likelihood of the person concerned causing immediate and serious harm to himself or herself or to other persons' (the 'risk criterion'); (b) 'because of the severity of the illness, disability or dementia, the judgement of the person concerned is so impaired that failure to admit the person to an approved centre would be likely to lead to a serious deterioration in his or her condition or would prevent the administration of appropriate treatment that could be given only by such admission, and the reception, detention and treatment of the person concerned in an approved centre would be likely to benefit or alleviate the condition of that person to a material extent' (the 'treatment criterion'); or (c) both (a) and (b).

We also recorded the date involuntary status was terminated and method by which it was terminated, categorised as follows: (a) detention order revoked by responsible consultant psychiatrist, (b) detention order revoked by mental health tribunal, (c) detention order expired and not renewed, or (d) patient transferred to another hospital while still detained.

We obtained population figures from the Irish national census (www.cso.ie/en/census) and national psychiatric admission figures from the Health Research Board's published report on Activities of Irish Psychiatric Units and Hospitals 2014 (Daly \& Walsh, 2015). For all rates, the denominator is the total population in the area (regardless of age).

\section{Ethics}

This study was approved by the Joint Research Ethics Committee of St James's Hospital and Tallaght Hospital. The study was performed in accordance with the Declaration of Helsinki (World Medical Association, 2008) and Data Protection Guidelines on Research in the Health Sector (Data Protection Commissioner, 2007). Data were stored on a password-protected research computer in a locked research office. Data were anonymised and encrypted. Data protection legislation was adhered to and patient confidentiality protected at all times. 


\section{Statistics}

We stored and analysed data using IBM Statistical Package for the Social Sciences Statistics (Version 24). Data were normally distributed except where specified otherwise. For bi-variable analyses, we used Student's $t$-test and analysis of variance for continuous variables and Pearson's $\chi^{2}$ tests for categorical variables. For multi-variable analysis, we generated a multi-variable, logistic regression model with admission status as the dependent variable (voluntary $v$. involuntary for all or part of the admission). Independent variables entered in the model were gender, age, occupation, marital status and diagnosis. We tested the model for multicollinearity, which is when one or more variables are so closely related to each other that the model cannot reliably distinguish the independent effects of each. To test for this, we calculated a 'tolerance value' for each independent variable; tolerance values below 0.25 indicate possible multicollinearity, and tolerance values below 0.10 indicate significant problems with multicollinearity (Katz, 1999).

\section{Results}

Over the 18-month-period studied (1 January 2014 to 30 June 2015), there were 948 admissions of which 820 $(86.5 \%)$ were voluntary and $128(13.5 \%)$ were involuntary (i.e. all or part of the admission was on an involuntary basis). This yields an annual admission rate of 346.7 admissions per 100000 population per year (Table 1). The voluntary admission rate was 299.9 per 100000 population per year and the involuntary admission rate was 46.8 per 100000 population per year.

Women accounted for $48.5 \%(n=460)$ of all admissions and $32.8 \%(n=42)$ of involuntary admissions. Almost $18 \%$ of male admissions were involuntary (17.6\%) compared to $9.1 \%$ of female admissions (Pearson's $\chi^{2} 14.623, p<0.001$ ). Mean age at admission was 41.4 years (range 16-91; S.D. 15.3); this did not differ between voluntary and involuntary patients $(t=1.379$, $p=0.168)$.

Involuntary patients were more likely to be single (i.e. never married) than voluntary patients $(80.5 \%$ and $64.5 \%$, respectively; Pearson's $\chi^{2} 13.135, p=0.011$ ). Over half of all patients were unemployed (58.9\%) and this did not differ significantly between involuntary and voluntary patients $(69.5 \%$ and $57.2 \%$, respectively; Pearson's $\left.\chi^{2} 7.432, p=0.059\right)$.

\section{Diagnosis and duration of admission}

Similar to national data, affective disorders had the highest overall admission rate in our study (Table 1) and among voluntary patients, while schizophrenia and related disorders were the most common diagnoses among involuntary patients, accounting for $60.9 \%$ of involuntary admissions in our study (compared to $42.1 \%$ nationally).

More than one-third of patients in the suburban area (39.2\%) were discharged within 1 week of admission and over three quarters $(76.1 \%)$ were discharged within 1 month; these are slightly higher than comparable national figures $(29.9 \%$ and $67.0 \%$, respectively)

Table 1. Clinical diagnoses among all psychiatric admissions (voluntary and involuntary) in Ireland (2014) and a suburban area (Dublin south west) (1 January 2014 to 30 June 2015)

\begin{tabular}{|c|c|c|c|c|c|c|}
\hline \multirow[b]{3}{*}{ Diagnostic grouping } & \multicolumn{6}{|c|}{ Rate of admission per 100000 population } \\
\hline & \multicolumn{2}{|c|}{ All patients } & \multicolumn{2}{|c|}{ Voluntary patients } & \multicolumn{2}{|c|}{ Involuntary patients } \\
\hline & $\begin{array}{l}\text { Ireland } \\
\text { (national) }^{\mathrm{a}}\end{array}$ & $\begin{array}{l}\text { Dublin south } \\
\text { west suburban } \\
\text { area }\end{array}$ & $\begin{array}{l}\text { Ireland } \\
\text { (national) }^{\mathrm{a}}\end{array}$ & $\begin{array}{l}\text { Dublin south } \\
\text { west suburban } \\
\text { area }\end{array}$ & $\begin{array}{l}\text { Ireland } \\
\text { (national) }^{\mathrm{a}}\end{array}$ & $\begin{array}{l}\text { Dublin south } \\
\text { west suburban } \\
\text { area }\end{array}$ \\
\hline Affective disorders & 150.6 & 118.1 & 137.4 & 105.7 & 13.2 & 12.4 \\
\hline $\begin{array}{l}\text { Schizophrenia, schizotypal and } \\
\text { delusional disorders }\end{array}$ & 77.2 & 92.2 & 58.2 & 63.6 & 18.9 & 28.5 \\
\hline Other and unspecified & 39.3 & 4.0 & 34.8 & 3.7 & 4.6 & 0.4 \\
\hline Neurosis & 33.3 & 50.8 & 32.4 & 49.0 & 0.9 & 1.8 \\
\hline Alcoholic disorders & 28.7 & 11.7 & 27.8 & 11.7 & 0.9 & 0 \\
\hline $\begin{array}{l}\text { Personality and behavioural } \\
\text { disorders }\end{array}$ & 26.9 & 40.6 & 25.2 & 39.9 & 1.7 & 0.7 \\
\hline Other drug disorders & 19.9 & 26.0 & 17.6 & 23.8 & 2.2 & 2.2 \\
\hline Organic disorders & 12.0 & 3.3 & 9.5 & 2.6 & 2.5 & 0.7 \\
\hline Total & 387.9 & 346.7 & 342.9 & 299.9 & 44.9 & 46.8 \\
\hline
\end{tabular}

${ }^{a}$ Daly \& Walsh (2015). 
(Daly \& Walsh, 2015). The mean duration of admission for involuntary patients in the suburban area (59.4 days, S.D. 98.0) was substantially longer than that for voluntary patients (18.9 days, S.D. $38.4 ; t=-8.404$, $p<0.001$ ), and involuntary patients spent a mean of 56.0 days with involuntary status (s.D. 111.7).

The 'treatment criterion' of the Mental Health Act 2001 was the sole basis for $61.9 \%$ of involuntary admissions in the suburban area; that is, 'because of the severity of the illness, disability or dementia, the judgement of the person concerned is so impaired that failure to admit the person to an approved centre would be likely to lead to a serious deterioration in his or her condition or would prevent the administration of appropriate treatment that could be given only by such admission, and the reception, detention and treatment of the person concerned in an approved centre would be likely to benefit or alleviate the condition of that person to a material extent'.

The 'risk criterion' was the sole basis for $11.9 \%$ of involuntary admissions; that is, 'because of the illness, disability or dementia, there is a serious likelihood of the person concerned causing immediate and serious harm to himself or herself or to other persons'. Both criteria were used as a basis for $26.3 \%$ of involuntary admissions.

Involuntary patients admitted under the 'treatment criterion' did not differ from those admitted under the 'risk criterion' in terms of age, occupation or marital status, but use of the 'treatment criterion' was associated with male gender and a diagnosis of schizophrenia or a related disorder (Table 2). Involuntary status was terminated following revocation of the order by the psychiatrist in $94.1 \%$ of cases, with $4.2 \%$ revoked by tribunals and $1.7 \%$ of patients transferred to another hospital while still detained.

\section{Correlates of involuntary admission status}

Table 3 outlines the results of multi-variable analysis of correlates of involuntary admission status. Involuntary admission was significantly associated with male gender (odds ratio: 1.55; 95\% confidence interval: 1.02-2.35), single marital status (i.e. never married) and having a diagnosis of schizophrenia or related disorders; and was not associated with occupation or age (odds ratio: 1.00; 95\% confidence interval: 0.99-1.01). This model accounted for $8.1 \%$ of variance in admission status between patients, meaning that $91.9 \%$ of the variability in admission status is not explained by factors included in the model. For each independent variable in the model we calculated a 'tolerance value' and all tolerance values were greater than 0.25 indicating no significant problems with multicollinearity (Katz, 1999).

\section{Discussion}

\section{Summary of main findings}

The overall rate of admission (including both voluntary and involuntary patients) in the suburban area over the 18-month-period studied (1 January 2014 to 30 June 2015) was 346.7 per 100000 population per year, which was lower than the national rate (387.9) (Table 1). The rate of involuntary admission in this area (46.8 involuntary admissions per 100000 population per year) was, however, comparable with the national rate (44.9). On multi-variable testing, male gender, being single (i.e. never married) and having a diagnosis of schizophrenia or related disorders were independent predictors of involuntary admission status, but most of the variance in admission status (91.9\%) remained unexplained even after taking account of these factors.

Overall these findings indicate a rise in the involuntary admission rate in this suburban area since 20072011, when the rate was 33.8 involuntary admissions per 100000 population per year, which was substantially lower than the national rate at that time (48.6) (McManus et al. 2015). By way of contrast, the involuntary admission rate in Dublin's north inner-city was 71.2 per 100000 population per year between 2008 and 2014, which was higher than the national rate and the rate in in south west Dublin city (Curley et al. 2016). Despite the recent increase, however, the rate in south west Dublin in 2014/2015 (46.8) has not yet reached the rates in the inner-city.

Our results confirm the previously described association between male gender and involuntary status (Cunningham, 2012; Curley et al. 2016) but we found no link with age or occupation. There was, however, a relationship between involuntary admission and single marital status but the literature is notably inconsistent on this point, so further work is needed ( $\mathrm{Ng} \&$ Kelly, 2012; Van der Post et al. 2012; Kelly et al. 2015; Curley et al. 2016).

A diagnosis of schizophrenia or a related illness is commonly associated with involuntary status in Ireland and elsewhere (Cunningham, 2012; Ng \& Kelly, 2012; Van der Post et al. 2012). In 2014, at national level, schizophrenia and related diagnoses had the highest rate of involuntary admission of any diagnosis in Ireland, at 18.9 per 100000 population per year, followed by affective disorders, at 13.2 (Daly \& Walsh, 2015, table 1). In our study, we also found that schizophrenia had the highest rate of involuntary admission with 28.5 involuntary admissions per 100000 population per year in 2014/2015, compared to 12.4 for affective disorders.

Between 2007 and 2011, schizophrenia and related disorders accounted for $60 \%$ of involuntary admission in the suburban area studied (McManus et al. 2015). In our study, we found that schizophrenia and related 
Table 2. Comparison of involuntary patients admitted under the 'risk' and 'treatment criteria' of the Mental Health Act 2001 in a suburban area (Dublin south west) (1 January 2014 to 30 June 2015)

\begin{tabular}{|c|c|c|c|c|c|}
\hline \multirow[b]{2}{*}{ Variables } & \multicolumn{3}{|c|}{ Mental Health Act 2001 involuntary admission criteria } & \multicolumn{2}{|l|}{ Statistical test } \\
\hline & 'Risk criterion'a & 'Treatment criterion' ${ }^{\mathrm{b}}$ & $\begin{array}{l}\text { Both the 'risk criterion' } \\
\text { and the 'treatment } \\
\text { criterion' }\end{array}$ & Test statistic & $p$ \\
\hline \multicolumn{6}{|l|}{ Gender } \\
\hline Female & $64.3 \%$ & $26.0 \%$ & $35.5 \%$ & \multirow{2}{*}{$\begin{array}{l}\text { Pearson's } \\
\chi^{2}=7.883\end{array}$} & \multirow[t]{2}{*}{0.019} \\
\hline Male & $35.7 \%$ & $74.0 \%$ & $64.5 \%$ & & \\
\hline Mean age in years (S.D.) & $41.07(21.01)$ & $39.75(17.01)$ & $40.03(13.67)$ & ANOVA $F=0.037$ & 0.964 \\
\hline \multicolumn{6}{|l|}{ Occupation } \\
\hline Unemployed & $57.1 \%$ & $71.2 \%$ & $74.2 \%$ & \multirow{4}{*}{$\begin{array}{l}\text { Pearson's } \\
\chi^{2}=11.064\end{array}$} & \multirow[t]{4}{*}{0.086} \\
\hline Employed & $21.4 \%$ & $26.0 \%$ & $19.4 \%$ & & \\
\hline Student & $7.1 \%$ & $2.7 \%$ & $0 \%$ & & \\
\hline Retired & $14.3 \%$ & $0 \%$ & $6.5 \%$ & & \\
\hline \multicolumn{6}{|l|}{ Marital status } \\
\hline Single & $78.6 \%$ & $83.6 \%$ & $74.2 \%$ & \multirow{5}{*}{$\begin{array}{l}\text { Pearson's } \\
\chi^{2}=5.195\end{array}$} & \multirow[t]{5}{*}{0.736} \\
\hline Married & $7.1 \%$ & $12.3 \%$ & $12.9 \%$ & & \\
\hline Separated & $7.1 \%$ & $1.4 \%$ & $6.5 \%$ & & \\
\hline Divorced & $0 \%$ & $1.4 \%$ & $3.2 \%$ & & \\
\hline Widowed & $7.1 \%$ & $1.4 \%$ & $3.2 \%$ & & \\
\hline \multicolumn{6}{|l|}{ Diagnosis } \\
\hline Affective disorders & $21.4 \%$ & $19.2 \%$ & $41.9 \%$ & \multirow{8}{*}{$\begin{array}{l}\text { Pearson's } \\
\chi^{2}=37.590\end{array}$} & \multirow[t]{8}{*}{$<0.001$} \\
\hline $\begin{array}{l}\text { Schizophrenia, schizotypal } \\
\text { and delusional disorders }\end{array}$ & $28.6 \%$ & $72.6 \%$ & $51.6 \%$ & & \\
\hline Other and unspecified & $7.1 \%$ & $0 \%$ & $0 \%$ & & \\
\hline Neurosis & $7.1 \%$ & $2.7 \%$ & $3.2 \%$ & & \\
\hline $\begin{array}{l}\text { Personality and behavioural } \\
\text { disorders }\end{array}$ & $7.1 \%$ & $1.4 \%$ & $0 \%$ & & \\
\hline Other drug disorders & $14.3 \%$ & $4.1 \%$ & $3.2 \%$ & & \\
\hline Organic disorders & $14.3 \%$ & $0 \%$ & $0 \%$ & & \\
\hline Total & $100 \%$ & $100 \%$ & $100.0 \%$ & & \\
\hline
\end{tabular}

ANOVA, Analysis of variance.

a 'Risk criterion': The person has 'mental disorder' and 'because of the illness, disability or dementia, there is a serious likelihood of the person concerned causing immediate and serious harm to himself or herself or to other persons' [Mental Health Act 2001, Section 3(1)(a)].

b 'Treatment criterion': The person has 'mental disorder' and '(i) because of the severity of the illness, disability or dementia, the judgment of the person concerned is so impaired that failure to admit the person to an approved centre would be likely to lead to a serious deterioration in his or her condition or would prevent the administration of appropriate treatment that could be given only by such admission, and (ii) the reception, detention and treatment of the person concerned in an approved centre would be likely to benefit or alleviate the condition of that person to a material extent' [Mental Health Act 2001, Section 3(1)(b)].

disorders still accounted for the same proportion of involuntary admissions in this area in 2014/2015 $(60.9 \%)$. This was higher than the figure for Ireland as a whole $(42.1 \%)$ (Daly \& Walsh, 2015), suggesting that schizophrenia is an especially important driver of involuntary admission in this suburban area compared to Ireland as a whole.

\section{Strengths and limitations of the present study}

This study addresses an important issue, psychiatric admission status, which has considerable implications in terms of human rights, use of coercion (Ranieri et al. 2015) and various other matters, most notably therapeutic relationships. Other methodological strengths include the examination of a range of variables and covariates commonly associated in different ways with admission status, including gender, age, occupation, marital status and clinical diagnosis, as well as duration of admission, criteria for involuntary admission, duration as an involuntary patient and reason for termination of involuntary status. We used clinical diagnoses coded using the International Classification of Diseases, Volume 10 (World Health Organisation, 1992) and 
Table 3. Multi-variable analysis of correlates of involuntary admission status in a suburban area (Dublin south west) (1 January 2014 to 30 June 2015)

\begin{tabular}{lrrr}
\hline Variables & \multicolumn{1}{l}{$\beta$} & Wald & \multicolumn{1}{l}{$p$} \\
\hline Gender & 0.437 & 4.176 & 0.041 \\
Age & 0.000 & 0.002 & 0.961 \\
Occupation & -0.139 & 0.838 & 0.360 \\
Marital status & -0.341 & 6.177 & 0.013 \\
Diagnosis & -0.322 & 16.776 & $<0.001$ \\
Constant & -0.333 & 0.232 & 0.630 \\
\hline
\end{tabular}

The dependent variable in this multi-variable, logistic regression model was admission status (voluntary $v$. involuntary for all or part of the admission). $R^{2}=8.1 \%$; $p<0.001$.

compared our results with data from the same service between 2007 and 2011, and with national data.

Limitations include the fact that our research is based in a specific suburban area of south west Dublin, which reduces generalisability to other areas. Other limitations include the fact that we did not examine certain variables (e.g. country of origin, insight, deprivation), which might well relate to admission status (Kelly et al. 2004; Expert Group on Mental Health Policy, 2006). We also recorded only one diagnosis per patient (when some may have had two or more), and our final multi-variable model had low predictive power (8.1\%), limiting the conclusions that can be drawn from it. This might be attributable, at least in part, to the fact that we selected the independent variables for inclusion in our model based on both their possible relevance to admission status and the fact that they were available from existing hospital data sources. Other variables (e.g. number of previous admissions, forensic history, etc.) merit study in this context in the future.

The diagnosis variable in this study also merits comment. National data on diagnoses were derived from the Health Research Board which collates diagnoses submitted by psychiatry inpatient units around Ireland (Daly \& Walsh, 2015), while diagnostic data for south west Dublin were derived from a single inpatient unit (in Tallaght Hospital). As a result, there may be greater diagnostic variation in the national data compared to the south west Dublin data and that might account for some of the observed differences between the two. For example, 39.3 admissions per 100000 population per year at national level were for 'other and unspecified' disorders, compared to just 4.0 in south west Dublin. While there is no particular reason to believe that this 'other and unspecified' category includes a disproportionate number of people with schizophrenia, further unpacking of that category would be useful for future studies.
Finally, we did not have access to national data at individual level, so it was not possible to perform a statistical comparison of local and national rates; we relied instead on summary national statistics published by the Health Research Board (Daly \& Walsh, 2015). This limits the generalisability of our findings.

\section{Conclusions}

Research into patterns and correlates of involuntary admission is important in seeking to balance the individual's right to liberty with the right to treatment and various other concerns. In this study, we found that the rate of involuntary admission in the suburban area studied increased between 2007-2011 and 2014/2015, but that the overall admission rate in this area is still below the national rate and the involuntary admission rate is comparable with the national rate. Multi-variable testing demonstrated that diagnosis is the strongest driver of involuntary admission in this suburban area, as schizophrenia and related disorders account for $60.9 \%$ of involuntary admissions in south west Dublin, compared to $42.1 \%$ nationally.

We conclude that while much of the variance in involuntary admission remains unexplained, schizophrenia is an especially important driver of involuntary admission in this suburban area compared to the rest of Ireland.

\section{Acknowledgement}

This paper contains Irish Public Sector Information licensed under a Creative Commons Attribution 4.0 International (CC BY 4.0) licence. The authors are very grateful to the editor and reviewers for their comments and suggestions.

\section{Conflicts of Interest}

None.

\section{Ethical Standards}

The authors assert that all procedures contributing to this work comply with the ethical standards of the relevant national and institutional committee on human experimentation with the Helsinki Declaration of 1975 , as revised in 2008. The study protocol was approved by the ethics committee of each participating institution.

\section{Financial Support}

This research received no specific grant from any funding agency, commercial, or not-for-profit sectors. 


\section{References}

Cunningham G (2012). Analysis of episodes of involuntary re-admission in Ireland (2007-2010). Irish Journal of Psychological Medicine 29, 180-184.

Curley A, Agada E, Emechebe A, Anamdi C, Ng XT, Duffy R, Kelly BD (2016). Exploring and explaining involuntary care: the relationship between psychiatric admission status, gender and other demographic and clinical variables. International Journal of Law and Psychiatry 47, 53-59.

Daly A, Walsh D (2015). Activities of Irish Psychiatric Units and Hospitals 2014. Health Research Board: Dublin.

Data Protection Commissioner (2007). Data Protection Guidelines on Research in the Health Sector. Data Protection Commissioner: Dublin.

Expert Group on Mental Health Policy (2006). A Vision for Change: Report of the Expert Group on Mental Health Policy. The Stationery Office: Dublin.

Georgieva I, Bainbridge E, McGuinness D, Keys M, Brosnan L, Felzmann H, Maguire J, Murphy K, Higgins A, McDonald C, Hallahan B (2016). Opinions of key stakeholders concerning involuntary admission of patients under the Mental Health Act 2001. Irish Journal of Psychological Medicine. https:/ /doi.org/ 10.1017/ipm.2016.6.

Gostin L, Bartlett P, Fennell P, McHale J and Mackay R, (editors) (2010). Principles of Mental Health Law and Policy. Oxford University Press: Oxford.

Katz MH (1999). Multivariable Analysis. Cambridge University Press: Cambridge.

Kelly BD (2007). Ireland's Mental Health Act 2001. Psychiatric Bulletin 31, 21-24.

Kelly BD (2016). Hearing Voices: The History of Psychiatry in Ireland. Irish Academic Press: Dublin.

Kelly BD, Clarke M, Browne S, Gervin M, Kinsella A, Lane A, Larkin C, O'Callaghan E (2004). Clinical predictors of admission status in first episode schizophrenia. European Psychiatry 19, 67-71.

Kelly BD, Emechebe A, Anamdi C, Duffy R, Murphy N, Rock C (2015). Custody, care and country of origin: demographic and diagnostic admission statistics at an inner-city adult psychiatry unit. International Journal of Law and Psychiatry 38, 1-7.

McManus S, McDonnell B, Whitty P (2015). Rate of involuntary admission in Dublin South West: a 5-year retrospective review. Irish Journal of Psychological Medicine $32,341-345$.
Murray I, Hallahan B, McDonald C (2009). Has the Mental Health Act 2001 altered the clinical profile of involuntary admissions? Irish Journal of Psychological Medicine 26, 179-182.

Ng XT, Kelly BD (2012). Voluntary and involuntary care: three-year study of demographic and diagnostic admission statistics at an inner-city adult psychiatry unit. International Journal of Law and Psychiatry 35, 317-326.

Nwachukwu I, Crumlish N, Heron EA, Gill M (2010). Irish Mental Health Act 2001: impact on involuntary admissions in a community mental health service. The Psychiatrist 34, 436-440.

Ramsay H, Roche E, O'Donoghe B (2013). Five years after implementation: a review of the Mental Health Act 2001. International Journal of Law and Psychiatry 36, 83-91.

Ranieri V, Madigan K, Roche E, Bainbridge E, McGuinness D, Tierney K, Feeney L, Hallahan B, McDonald C, O'Donoghue B (2015). Caregivers' perceptions of coercion in psychiatric hospital admission. Psychiatry Research 228, 380-385.

Salize J, Dressing H (2004). Epidemiology of involuntary placement of mentally ill people across the European Union. British Journal of Psychiatry 184, 163-186.

Smyth S, Casey D, Cooney A, Higgins A, McGuinness D, Bainbridge E, Keys M, Georgieva I, Brosnan L, Beecher C, Hallahan B, McDonald C, Murphy K (2016). Qualitative exploration of stakeholders ' perspectives of involuntary admission under the Mental Health Act 2001 in Ireland. International Journal of Mental Health Nursing. http:/ / onlinelibrary.wiley.com/doi/10.1111/inm.12270/full.

Van der Post L, Mulder C, Schoevers R, Dekker J, Beekman A (2012). Factors associated with higher risk of emergency compulsory admission for immigrants: a report from the ASAP study. International Journal of Social Psychiatry 58, 374-380.

World Health Organisation (1992). International Classification of Diseases, 10th edn. World Health Organisation: Geneva.

World Medical Association (2008). WMA Declaration of Helsinki - Ethical Principles for Medical Research Involving Human Subjects. World Medical Association: FerneyVoltaire.

Zinkler M, Priebe S (2002). Detention of the mentally ill in Europe - a review. Acta Psychiatrica Scandinavica 106, 3-8. 